\title{
Making the Best of all Resources: How Indonesian Household Recipients Use the CCT Allowance
}

\author{
Muhammad Syukri, Sirojuddin Arif, Meuthia Rosfadhila and \\ Widjajanti Isdijoso
}

\begin{abstract}
Based on a qualitative study in four villages in Indonesia, this article explores how the conditional cash transfer (CCT) recipient households use the CCT funds. In 2007, the Government of Indonesia introduced a household CCT programme called Program Keluarga Harapan (PKH, Family of Hope Programme) with the aim of providing the chronic poor with cash transfers to help them better access basic education and healthcare services. The study found that recipients have used the transfer not only to fulfil their basic education and healthcare needs, but also to grow their assets whenever possible. Furthermore, by comparing urban and rural cases, where both informal social security and the real value of CCT funds differ, it seems that welfare improvements as a result of the cash transfers are more significant in rural than in urban areas.
\end{abstract}

\begin{abstract}
1 Introduction
This article aims to highlight the use of conditional cash transfer (CCT) funds by programme recipients in Indonesia. What expenditures do the recipients cover with the funds? Despite a large body of knowledge produced on the impact of CGTs in many countries, very little is known about the allocation of the funds by programme recipients. Most studies on this subject focus on the impact of the programme on children's education and healthcare (as well as pregnant mothers' healthcare) as the main objective of the programme. ${ }^{1}$ While many have revealed a relationship between the programme and improvements in children's healthcare and education, the processes involved, from the perspective of the recipients, have not been much investigated. Such information would be of significant value in improving programme design and implementation. By focusing on how recipients allocate the funds, we hope that this article may contribute to answering this question.
\end{abstract}

Data for the article are drawn from a study conducted by The SMERU Research Institute on the role of women in the CGT programme in Indonesia. ${ }^{2}$ The study, which is qualitative in nature, covers four villages in two provinces covered by the programme. In each province, one rural and one urban village were selected in order to grasp the variations between these different geographical categories. The two provinces are West Java and East Nusa Tenggara. The urban and rural villages in West Java province are located in Kabupaten (District) Cirebon. In East Nusa Tenggara province, one village was selected from Kota (City) Kupang to represent the condition of an urban area and the other was selected from Kabupaten Timor Tengah Selatan (TTS) to represent the rural one.

The fieldwork for this study was conducted from February to May 2009. In each study site, SMERU researchers conducted in-depth interviews with four recipient households. The researchers interviewed not only mothers or female members of the recipient households, but also the husbands and children in order to better understand the intra-household dynamics of every household. Furthermore, to better understand the impact of the programme at the

IDS Bulletin Volume 41 Number 4 July 2010 @ 2010 The Authors. Journal compilation (c) Institute of Development Studies Published by Blackwell Publishing Ltd, 9600 Garsington Road, Oxford OX4 2DQ, UK and 350 Main Street, Malden, MA 02148, USA 


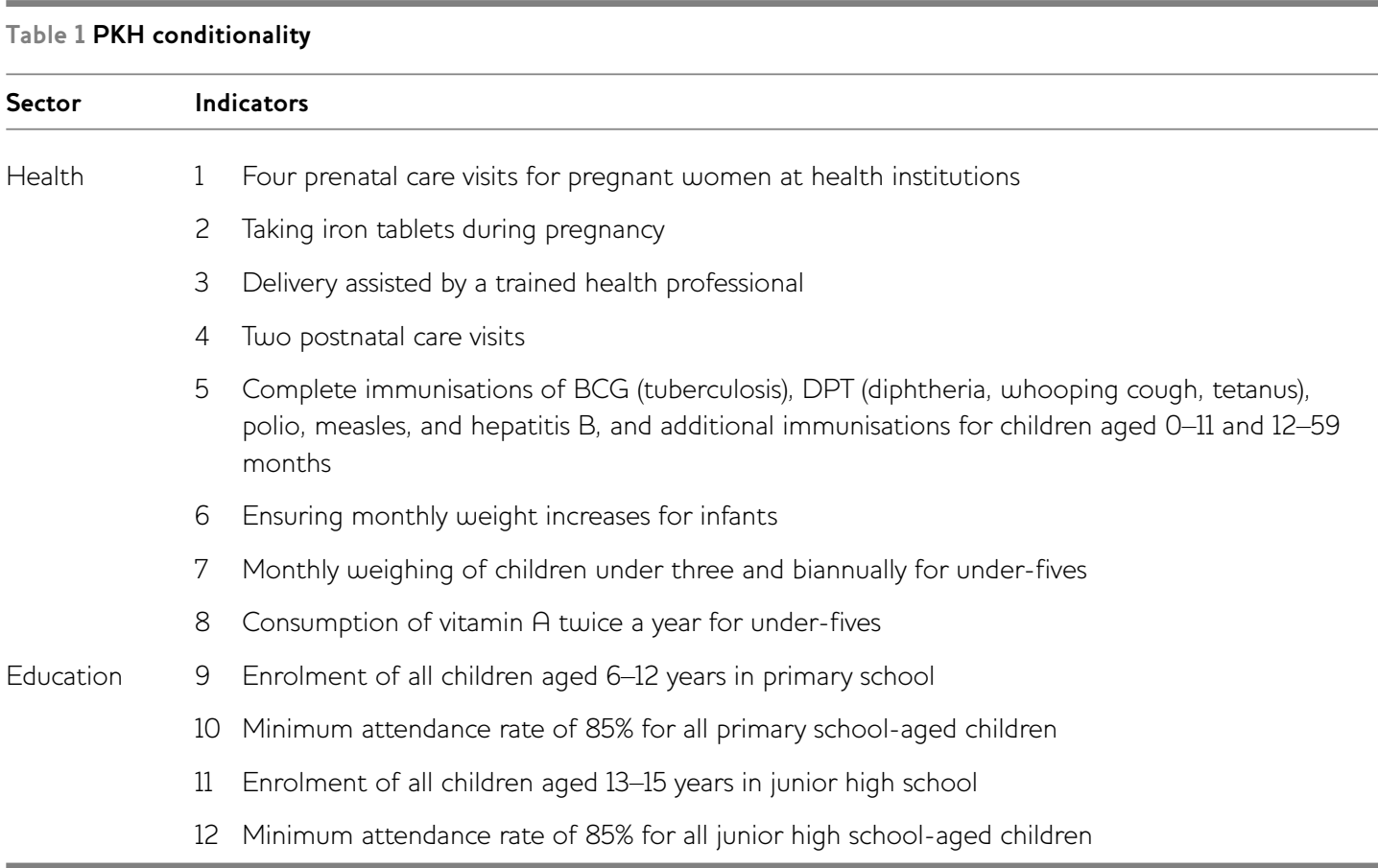

household level, in each village, similar interviews were also conducted with another two households which were similar but which did not receive the cash transfers. Information on the social context and programme implementation in each study site was also gathered through interviews with key informants and focus group discussions (FGDs). These key informants included government officials at the district, subdistrict, and village levels as well as education and healthcare service providers. In addition, two FGDs were carried out with community members (in separate male and female groups) at the village level and another with officials at the subdistrict level. This made a total of 24 households, 12 FGDs, and more than 25 interviews with key informants.

\section{Indonesia's CCT Programme - The PKH}

In order to improve the provision of promotive social protection for the chronically poor, in 2007 the Government of Indonesia (GoI) embarked on piloting a conditional cash transfer (CCT) programme called Program Keluarga Harapan (PKH 2007). The programme is planned to run until 2015 and aims to reach approximately 6.5 million chronically poor households. Focusing on the demand side, especially in educational attainment and health, it is hoped that children from chronically poor households can escape the intergenerational poverty trap. For this purpose, the government provides targeted households with a cash transfer ranging from Rs600,000 to Rs2,200,000 per year. ${ }^{3}$ The amount is defined by the number of household members considered as the target group of the programme, namely babies and children aged $0-6$ years, children and teenagers aged $6-15$ years or teenagers under 18 years who have not completed primary school, and pregnant or breastfeeding mothers.

Compared to household expenses, the real benefit of the cash transfer differs by region and between rural and urban areas, and according to the degree of monetisation of the local economy. However, in general, the real benefit of the transfer may range from 20 to 80 per cent of the monthly household expenditure.

The programme's charter specifies that its main objectives are to improve: socioeconomic conditions; children's education levels; and the health and nutritional status of pregnant and breastfeeding women, and children under five, among the household recipients. For this purpose, the programme recipient will receive cash transfers regularly from the government conditional on their fulfillment of the requirements stated by the programme (Table 1).

The independent compliance monitoring system, however, is still lacking. According to programme guidelines, programme managers will monitor 


\begin{tabular}{|c|c|c|c|c|c|c|}
\hline \multirow[t]{2}{*}{ Village (size; population) } & \multicolumn{2}{|c|}{ Geographical location } & \multicolumn{2}{|c|}{ Regional characteristics } & \multicolumn{2}{|c|}{ Economic condition } \\
\hline & Inland & Coastal & Rural & Urban & $\begin{array}{l}\text { Highly } \\
\text { monetised }\end{array}$ & $\begin{array}{l}\text { Less } \\
\text { monetised }\end{array}$ \\
\hline $\begin{array}{l}\text { Village Urban A, Cirebon, West Java } \\
\text { (Size } 93 \text { Ha; Pop. 6,288) }\end{array}$ & & $\sqrt{ }$ & & $\sqrt{ }$ & $\sqrt{ }$ & \\
\hline $\begin{array}{l}\text { Village Rural B, Cirebon, West Java } \\
\text { (Size } 400 \text { Ha; Pop. 7,806) }\end{array}$ & $\sqrt{ }$ & & $\sqrt{ }$ & & $\sqrt{ }$ & \\
\hline $\begin{array}{l}\text { Village Urban C, Kupang, East Nusa Tenggara } \\
\text { (Size } 41 \text { Ha; Pop. 4,661) }\end{array}$ & & $\sqrt{ }$ & & $\sqrt{ }$ & $\sqrt{ }$ & \\
\hline $\begin{array}{l}\text { Village Rural D, TTS, East Nusa Tenggara } \\
\text { (Size 1,800 Ha; Pop. 2,500) }\end{array}$ & $\sqrt{ }$ & & $\sqrt{ }$ & & & $\sqrt{ }$ \\
\hline
\end{tabular}

the fulfillment of the conditionality by asking service providers - the schools and the health centres - to fill in monitoring forms that will be distributed and collected by the post office. However, until the time of this study, this system has not been running. The service providers recently received information regarding the monitoring form, but still have many questions about the process. Some schools and health centres do not know which recipient households are to be monitored. Thus, only the field supervisor is currently checking progress.

\section{Understanding the context: the lives of the chronically poor}

In terms of socioeconomic background, this study covers various factors which may influence the lives not only of the chronically poor but also of the general population. As can be briefly seen in Table 2, this may be broken down into inland and coastal, rural and urban, and highly and less monetised. Even though these categories do not necessarily denote the typical conditions for every area, as they overlap with each other, taking these categories into consideration may enable us to get a better understanding of the conditions and the livelihoods of the chronically poor who receive the CGT in each study site.

In rural areas, the chronically poor rely primarily on agriculture. However, regional variations can be clearly seen between those living in Rural Village B of West Java and those living in Rural Village D of East Nusa Tenggara. In Village B, which has a more monetised economy, none of the chronically poor own land, while all the respondents in Village D have land which ranges from a quarter of a hectare to more than three hectares. The fact that these villagers are subsistence farmers may contribute to the lesser influence of money in their daily life. Local tradition also enables those who do not have access to farm land to request plots from a richer family by providing the landowner with sirihpinang (betel nuts and piper betel leaves) without paying any money, ${ }^{4}$ a custom that is still practiced today in the region. However, this does not mean that the villagers in Village $\mathrm{D}$ do not need cash income. Before the harvest, men usually seek non-farm jobs to earn money needed to pay expenses or utilities, which cannot be done by selling farm products, such as buying children's school uniforms. Since their land may not be sufficient, some people also work during the planting period to earn cash income to meet their daily needs. Nevertheless, compared with the chronically poor in Village B, it seems that money income is complementary to agricultural production. In contrast, chronically poor households in Village B have to rely on wages they earn either from agricultural works as their main source of income or other types of jobs they can do in-between the harvest and planting seasons.

It is worth noting that seasonality strongly affects the livelihoods of the chronically poor in this village. Located on a hill, the village is susceptible to strong winds that often destroy the crops. The dry and sloping land is also highly prone to landslides, which occur regularly. Therefore, although most villagers own farmland, their welfare conditions are not significantly different from those who do not own it. 
The fact that the chronically poor do not have any land is one of the main sources of their vulnerability. However, reliance on paid work is not easy in agricultural areas where agricultural employment is not always available, and nonfarm employment opportunities are also limited. In agriculture, most jobs are available only during planting and harvest seasons, so many people in Village B have to seek non-farm jobs either in or outside the village between the harvest season and the next planting period. If they are lucky, they may find work in the village. But it is often the case that jobs during this period are only halftime. In Village B, half-day wages range from Rs 15,000 to Rs20,000 (US\$1.70-2.20), while fullday work is paid Rs25,000 (US\$2.70) plus a package of lunch and dinner.

Due to their limited education and skills, it is also difficult for villagers to find better-paid jobs. Most of the respondents have only finished primary school, making them less competitive in the labour market. Many respondents in Village $\mathrm{B}$ migrate to the nearest cities or to Jakarta to undertake casual jobs as pedlars, unskilled labourers, construction workers, or domestic servants. On average, the monthly wage is usually less than Rs500,000 (US\$55.00). Most earn even less, only around Rs200,000-Rs300,000 (US\$22.00-33.00), an amount of which is definitely not enough to fulfil their basic needs. By a rough estimation, at least Rs25,000 (US\$2.70) per day is needed to cover their daily needs. ${ }^{5}$ It is because of such conditions that many respondents in Village B reported that they often have to get loans to support their limited, uncertain and fluctuating income.

In contrast, people's need for cash in Village D is significantly lower than that in Village B. Interviews with some respondents reveal that they need between Rs5,000 (US\$0.50) and Rs 10,000 (US\$1.00) per day to cover their daily expenditures. The reason is that they rarely have to buy staple food, usually corn, as they produce it themselves. They also have secondary crops such as banana, cassava and peanuts, which they can either sell for cash or consume. Under such conditions, the demand for cash is not as high as in Village B. They need it more to cover non-daily expenses, such as children's school expenses. For this, they may rely on non-food crops such as candlenut or tamarind, which are usually harvested once a year. Similarly to Village B, some people may also go to cities or other areas to seek paid jobs in carpentry or construction. Those with limited skills may sell firewood or animal fodder, or work as stone breakers. The demand for such paid jobs is higher during the pre-harvest period, especially if a household's previous year's harvest was not good.

In urban areas, the types of work undertaken by the chronically poor are more varied. As indicated in Table 2, both the urban study sites are located on the coast. While Village $\mathrm{A}$ is on the Java Sea coast, Village $\mathrm{C}$ is located on Kupang Bay. Nevertheless, it is interesting to note that the livelihoods of the chronically poor represent neither the characteristics of a coastal area nor those of a modern urban one. A very small number of respondents are involved in fishing or related activities. In Village A, most poor men are involved in non-fishing activities such as pedicab driving, sheepherding, construction, and labouring on fishing vessels. Interviews with some respondents indicate that the local labour market system is, to some extent, biased against the poor. Many of them previously worked as small-scale fishermen, but they were gradually excluded and shifted to other types of jobs such as pedicab driving. It is likely that poor women are more attached to fishing-related activities, especially as rajungan cutters,${ }^{6}$ in addition to their domestic tasks. Nevertheless, many women could not work in this sector, either due to the decrease of the rajungan catch in Cirebon during the last several years or other causes, such as the lack of skills or networks in the business.

In Urban Village $\mathrm{G}$, the number of poor men who work as fishermen is even smaller than in Urban Village A. Most of the poor men in Village $\mathrm{C}$ work in the service sector typical to urban areas in jobs such as newspaper delivery, small trading, motorcycle-taxi driving or construction. Their wives usually work as small traders managing small kiosks, or become housewives. Working mostly in the informal sector, their income is unstable. Based on a respondent's own estimation, they usually earn about Rs300,000 (US\$33.00) to Rs500,000 (US\$55.00) per month. According to some respondents, this amount is not enough to fulfil the basic needs of the entire family. Nevertheless, they hardly ever experience food scarcity and shortage. In the worst situations, they reduce food consumption from 
three times a day to twice a day, but none eats only once a day.

In terms of public service provision, the poor people in the areas studied are fortunate in having the main public services, particularly education and healthcare facilities, available in or around their neighbourhood. All the villages sampled in the urban as well as rural areas have more than one primary school and one villagelevel health post. In several villages, a primary school is available in most hamlets. The high schools and the larger healthcare facilities, on the other hand, are usually established in subdistrict capitals. Primary school students need no money for transport because they can reach their school on foot or by bicycle, while high school students, due to the distant location, usually have to take a bus or motorcycle taxi to go to school. The same thing also happens when people want to access the health centre in the subdistrict. For both education and healthcare services, the poor are not charged any fee. Since the government has implemented social protection programmes in the education and health sectors ${ }^{7}$ which cover the school fee and the healthcare fee, the only expenses the poor still have to pay are the non-fee school needs, such as transport, school uniform, pens and pencils, and transport expenses for healthcare.

\section{Existing support systems}

Communities in the study areas have long practiced traditional strategies to cope with their vulnerabilities. Thus, modern social protection institutions and strategies are scarce. Where such systems do exist, they are usually not easily accessible to the poor. The most common traditional strategy is to ask for help from the closest people such as relatives and friends. However, if the poor need material assistance in the form of money or goods, the strategy often does not work, as their relatives and friends are also poor. Even if the strategy is successful, it should be noted that in some areas such as in Village A and B, the assistance is not charity as both material and non-material assistances must be paid back.

The poor usually borrow money from neighbours and relatives to cover expenses for healthcare services, education, or customary activities. To fulfil high cost investment needs, such as opening a small kiosk, they tend to look for a loan from a more formal institution, whereas for daily household consumption needs, they generally seek help from local shops that sell goods on credit.

If the poor fail to get assistance from those closest to them, they may request a loan from richer people. In the sample villages, there are many kinds of loans. They range from money to goods (clothes, furniture, electronic appliances, and kitchen utensils) and labour or service; all are subject to interest. In Villages $\mathrm{C}$ and D, the interest rate is contractually specified based on the agreement of both parties and ranges from 10 per cent to 25 per cent per month. In Villages $\mathrm{A}$ and $\mathrm{B}$, even though the interest is not always determined through a contractual agreement, according to local custom, every time someone borrows money, as an expression of gratitude, the repayment should be larger. The amount of this 'gratitude money' is set in advance, but if the borrower does not pay back the debt with additional gratitude, it will be difficult for him or her to get another loan in the future. In addition, there are also many loan sharks (mostly people from outside the village), particularly in Village $\mathrm{B}$, who can easily provide loans and goods on credit but with a very high interest rate of up to 25 per cent per month.

In Village B, the village barn can give loans in the form of rice to its members in times of food shortage, ${ }^{8}$ which must be returned within a certain period of time with interest. In addition, women's savings and loan groups also provide loans to their members and operate similarly to the village barn. In Village D, a farmers' group provides loans to its members, who can borrow money for a maximum repayment time of three months with an interest rate of 10-15 per cent. In addition, a cooperative managed by a network of Protestant religious organisations also provides business loans to villagers, but these cannot be used for consumption. The increasing number of these formal financial institutions has reduced the role of the loan sharks.

In addition to the local support system, the government has also introduced many social protection programmes at the central and local levels. Prior to PKH, chronically poor households received support through programmes, including Raskin (Rice for the Poor), BLT (Unconditional Cash Transfer), BOS (School Operational Assistance), and Jamkesmas (Community Health 


\begin{tabular}{lllll}
\hline \multicolumn{1}{l}{ Table 3 Number of households and their use of PKH transfer } \\
\hline & $\begin{array}{l}\text { Education and } \\
\text { healthcare }\end{array}$ & Daily consumption & Asset accumulation & Other expenditures \\
\hline Urban: Village $A(n=4)$ & 4 & 3 & 2 & 2 \\
Urban: Village $C(n=4)$ & 4 & 3 & - & 1 \\
Rural: Village B $(n=4)$ & 4 & 4 & - & 2 \\
Rural: Village $D(n=4)$ & 4 & 3 & 4 & 1 \\
Total (n=16) & 16 & 13 & 6 & 6 \\
\hline
\end{tabular}

Source Field notes - respondents' information.

Insurance). Besides these, in the study areas, particularly in Village D, the farmers received government assistance in the form of a seed and fertiliser subsidy, while in Village $\mathrm{C}$, some poor fishermen received fishing nets. The poor have also taken advantage of community-targeted schemes such as the PNPM (National Program for Community Empowerment) that provides a block grant, based on community proposals. ${ }^{9}$

Apart from these central government interventions, the poor also receive many kinds of assistance from the local governments. In NTT, for instance, the elderly are part of a livestock assistance scheme, and receive an additional (to Raskin) rice subsidy. In West Java, primary school students from poor families also benefit from incentives provided by the governor (BAGUS/ Bantuan Gubernur untuk Siswa - Governor's Assistance for Students) in the form of direct cash transfers. The poor in NTT have also benefited from various programmes run by international, national, and local civil society organisations.

\section{Uses of the PKH transfer}

All the respondents claimed that CCTs made a significant contribution to easing their economic difficulties. As required by the programme's conditionality, all respondents claimed that they used the cash transfer mostly to pay expenses related to their children's education and/or healthcare, depending on the age of the children or the composition of household members. As indicated in Table 3, all the respondents claimed that they spent some or most of the cash transfer on expenses related to their children's education or healthcare, as required by the programme conditionality. Nevertheless, it is also worth noting that the cash transfer was also used for other household needs.
The general emphasis on healthcare and education may reflect, to some extent, the success of the programme's implementers in enforcing the conditionality, especially on the use of cash transfers. However, believing that recipients will use the money only in accordance with the programme's requirements without making any adjustment or modification may simplify the reality of implementation. Indeed, the fact that the recipients used the cash transfers for various purposes clearly indicates that they also have their own preferences. It is important, therefore, to scrutinise these other types of expenditures and their implications for the achievement of the programme's objectives in general. According to the guidelines, the PKH aims not only to reduce poverty or increase the socioeconomic conditions of the targeted chronically poor, but also more fundamentally, to develop the human resources, especially children, of the programme recipients' households so that they can escape from intergenerational poverty traps.

With regard to the use of the cash transfer, the programme guideline does not specify how recipients should use the money. It only provides general instructions on what they must do in order to meet the scheme's conditions (Table 2). People may therefore infer that the cash transfer should be used in accordance with this conditionality. However, it is likely that the recipients knew of the rules only from their field advisers without accessing the text themselves. As such, the way they spent the money was likely to be influenced by their field advisers' guidance.

In the programme's institutional structure, field advisers have a very important position. The guidelines state that the field adviser is the programme implementer at the subdistrict level 
- the lowest level of PKH's organisational structure. Their main task is to ensure that recipients receive their transfer on time and in the correct amount, and to help them comply with the conditionality. In practice, many respondents stated that the field advisers gave them advice as to how they should use the cash transfer. One of the most important things advised was that the recipients use the cash transfer only for education and healthcare needs. While education expenses may include buying school uniforms, footwear, books, pencils, etc. as well as paying transport costs and fulfilling many other things necessary to ensure their children's primary education, healthcare expenses may include medical checks, medicine, nutritional supplements and other healthcare components.

To emphasise this aspect, the field advisers in the study areas insisted on some restrictions or limitations to the use of the cash transfer. One respondent said that it was prohibited to use the cash transfer for buying tertiary or luxury goods, such as TVs or jewellery. The advisers insisted that recipients obey these regulations or that the government would stop the cash transfers. One of the field advisers even claimed that he randomly checked recipients' use of the cash transfer by asking for invoices/receipts for their spending on their children's education or healthcare. However, as will be further discussed, one of the field advisers suggested that recipients use the money for investments such as breeding livestock or repairing their houses, which are apparently not actually included in the programme's objectives.

Without having access to the guidelines, recipients were likely to be very much influenced by the field adviser's suggestions regarding how they should use the transfers. It was due to the field advisers' directions that children's school and healthcare expenses were claimed to be the first priority by the majority of the respondents. Many respondents stated that they were afraid that the amount of the cash transfer would be reduced or their names would be discarded from the programme if they did not comply with their field adviser's instructions.

Nevertheless, as indicated in Table 3, it is likely that recipients' use of the cash transfers was not directed solely by conditionality. In the context of chronic poverty, meeting daily food consumption needs often remained a big problem. Due to limited income, some respondents stated that they often had to buy food on credit from the local kiosk. Even to buy the cheap subsidised rice from the government, some respondents claimed that they had to get loans either from relatives or from moneylenders. This was because rice was usually sold in a monthly package of $15 \mathrm{~kg}$ and they had to pay out accordingly. Under such conditions, it is quite understandable that out of the 16 respondents, 13 said that they used the cash transfer for meeting their daily consumption needs. Most of them stated that they used some of the money to buy rice and vegetables or other side dishes. The food was not used only for the consumption of children less than six years old and pregnant mothers, as the programme targets suggested, but for all the household members. The respondents believed that such a practice did not conflict with the objectives of the programme, as food intake is necessary to maintain the health of not only the children but also the parents who have to take care of the children.

Some recipients however interpreted using the money for daily consumption needs of the whole family as contradicting the main goals of the programme. Only when they thought it necessary did they use the money to buy daily food. One respondent even did this with their children's permission. The parent thought that the money actually belonged to the children, so if the parent wanted to use it for purposes other than the targeted children's needs, they had to get permission from the children first. The portion of the transfer being spent on food consumption might reflect the household's capability to meet their basic consumption needs, which is an essential element for both health and education attainment. However, the fact that some households spent the cash transfer mostly on food is rather alarming, as it may reduce the capacity to invest more on the health and education costs necessary to achieve the programme's objectives.

Such deviation can be found even in targeted sectors such as education. Some recipients stated that the PKH cash transfer was used not only for their children who were attending primary and junior high school, which are the targets of the programme, but also for their older brothers or sisters who went to senior high school. For 
example, Rosana ${ }^{10}$ said that it was difficult for her to treat her older son, a senior high school student, differently from his younger brothers and sisters who were still in primary school. When she bought her younger children school uniforms with the CCT, she felt that she also had to buy her older son a school uniform (interview with female, 45 years old, from Village C, on 29 April, 2009). Another female respondent stated that she also used the money to pay the transport costs of her younger brother who went to senior high school (interview with female, 30 years old, from village A, 9 February, 2009).

Moreover, some households also used the cash transfer for other expenses which seem to have no direct relation with the main healthcare and education objectives of the programme. As indicated in Table 3, out of the 16 households, six reported the use of the transfer for asset accumulation and other expenditures. While the former includes some investments, like saving money in a bank account, repairing the house and buying livestock, the latter includes meeting such practical needs as repaying debts, paying water and electricity bills, giving money to other family members in need, or buying cooking utensils or clothes other than school uniform, which could be categorised as 'other' household expenditures. It is very likely that the poorer the household, the more the cash transfer is used to fulfil other household expenses besides education and healthcare as well as daily food consumption. In Village B, where most recipients are farm labourers who own no land and seem poorer than those in other villages, three (out of four) respondents acknowledged that the $\mathrm{PKH}$ cash transfer had helped them reduce their debts. On the other hand, in another village, Alan said that the main benefit of the programme was that it helped him meet his household's daily needs. His irregular income as a fishing worker had made it difficult for him to meet the relatively high cost of living in an urban area (interview with male, 39 years old, from Village C, on 29 April, 2009).

In contrast, it is also interesting to note that six households used the cash transfer toward asset accumulation: four households repaired their houses, one bought a pig, and one saved it in a bank. Except for the last, which was intended to finance the future education of the recipient's daughter, the other choices were far from the direct objectives of improving education and health condition of the target groups.

Nevertheless for the poor, especially for those living in chronic poverty, the problems and difficulties that they had to encounter every day were often more obvious than the programme's ideals. Explaining his reasoning, Dullah said that it was better to spend some of the cash transfer on 'big and strategic things' like repairing the house. For poor people like him, it seems impossible to repair his house with their own money. On the other hand, relying on others' help is not a good choice either. Therefore, with his wife's agreement, he used some of the PKH cash transfer to repair their house (interview with male, 45 years old, from Village A, on 16 February 2009).

Similarly, all the four households visited in Village D spent some of the transfer to repair their house or buy livestock. Martin said that he and his wife agreed to buy a pig (interview with male, 33 years old, from Village D, on 27 April, 2009). However, unlike other respondents in Villages A and B, who deliberately made the decision to repair their houses in their own interest, some explained that it was the field adviser who suggested they should do so. The field adviser told them that they should make, with the support from the cash transfer, some major improvements in their life such as repairing their houses, keeping livestock, or making other types of asset accumulation. The fact that the village is less monetised partly explains the possibility of such choices.

From the welfare function perspective, all this evidence indicates that the cash transfer has helped programme recipients increase their wellbeing or ease their economic burden. For some households, the amount of money they receive could be of significant value. Disbursed three times a year, the amount of the cash transfers received by the recipients varies according to their household dependents, but generally ranges from Rs200,000 (US\$22.00) to Rs733,000 (US\$81.00). In fact, the household income of a respondent briefly discussed in the previous section may fluctuate around Rs300,000-500,000 (US\$33.00-55.00) per month. With this additional income, many respondents stated that they could meet some household needs previously unmet by their limited income. Some reported that the cash transfers allowed them to 
reduce the frequency of loans they usually took from local stalls. Without such transfers, it might have been difficult for them, as in the case of other respondents who did not receive them, to reduce the frequency of their loans.

Nevertheless, from the programme implementer's perspective, particularly the field advisers and the programme management in general, it is considered as an indication for noncompliance by the recipients. The emphasis that the programme recipient should use the transfer for expenses directly related with children's education, the nutrition and healthcare of pregnant and breastfeeding mother and for children under five years old, rooted on the argument that improvement in this field requires not only the provision of resources, but also an overall change of programme recipient's attitude. While primary education is generally free, and primary or junior high schools are usually located at an affordable distance, parents still need money to send their children to school. Other than having to buy some basics such as school uniforms, books or pencils, some schools often ask for money for extracurricular activities. In the health sector, although public health centres are also available at an affordable distance and integrated health posts (posyandu) for children under five years old are also available in all the visited villages, health maintenance is not only determined by the availability of healthcare facilities. More important is people's awareness regarding the maintenance of their health. Maintaining children's health, for instance, requires, e.g. the provision of good nutrition. The success of the PKH thus, in the programme's management opinion, also requires behavioural changes on the part of recipients for them to prioritise the available funds for education and healthcare, or at least to fulfil the programme's conditionality.

Some respondents used some of the transfers, and sometimes the majority, for expenses other than those required by the direct programme's objectives. Practical needs including daily consumption and paying off debt often made it difficult for the recipients to allocate much of the money to long-term investments in healthcare and education. While the deviation might still be supporting the long-term goal of improving welfare, this still leads to the failure to meet the programme's conditionality, which is also exacerbated by the lack of a well established compliance monitoring system.

Although the programme provides some money to women, the decision-making pattern in the $\mathrm{PKH}$ recipient households is not different to the non-recipient households. For the women as the transfer recipients, the fact that their husbands' income was often not sufficient to meet all their household needs has provided a legitimate reason for them to use the money towards daily consumption and other household needs. Since the money was directly transferred to them, it has allowed them to manage its use. All interviewees reported that the spending of most of the money is in their control and not their husband's. Nevertheless, the evidence indicated that some husbands did take part in deciding on the use of the allowance, with regard to strategic uses of the money, such as repairing houses or buying livestock. Traditional gender roles mean that while decision over daily matters, especially daily food consumption belongs to the wife, control over strategic issues such as investment or buying big assets is more the husband's domain. Some husbands were also involved in the use of the transfer for asset accumulation.

\section{Conclusion}

Findings from the field show that the differences and complexities in the problems faced by the chronically poor in rural and urban areas have impacted on the benefits of the PKH cash transfer. In general, compared with poor people in rural areas, the urban poor face much greater economic instability. This is caused by uncertainty of income, lack of assets and resources, and greater dependence on monetary transactions rather than subsistence. Poverty in urban areas is more severe than rural poverty, and those living in areas most dependent on monetary transactions are also worse off. Therefore, the same amount of PKH cash is more beneficial in less monetised rural areas than in more monetised areas, whether urban or rural.

As we have seen above, although the programme's guideline does not explicitly restrict the use of the transfers, there is pressure from programme management to use them to meet education and healthcare needs. In some cases, this has led to conflict with $\mathrm{PKH}$ recipients who do not always spend the money according to the guidelines, partly due to the fact that daily 
consumption needs are more urgent than those of healthcare and education. However, this flexibility in the use of the transfers has allowed the PKH benefit to ease people's debt burden and to spread beyond the targeted beneficiaries, as well as to support asset accumulation that potentially increases households' future welfare.

\section{Policy relevance}

The above conclusions make it possible to argue for differentiating the amount of cash transfers received by the poor in rural and urban areas or between regions that are more or less dependent on monetary transactions, if the programme is expecting the same outcome across regions. This distinction will, however, make the programme more susceptible to conflict and the implementation more complex. On the other hand, such differentiation will be more effective in dealing with the different conditions of the poor in each area.

\section{Notes}

1 See, e.g. Skoufias and Parker (2001); Moore (2009) and Rawlings and Rubio (2003).

2 See Hutagalung, Arif and Suharyo (2009) for the background paper of the study.

3 For comparison, the 2009 national poverty lines in Indonesia are set at Rs222,123 per capita per month for urban area and Rs 179,835 per capita per month for rural area; and the poverty rates are estimated at 10.7 per cent in urban areas and 17.4 per cent in rural areas. Thus, the maximum amount of CC transfer is about 21 per cent (urban) and 25 per cent (rural) of the poverty line for a family consisting of four household members.

4 The legal status of the land varies from case to case. There is a case where the land being handed over is then certified under the recipient name; but in another case, the recipient is only provided with the right to farm but not to sell the land.

5 This is not to include bigger expenses, such as children's school uniforms or books, which are usually on a biannual or annual basis.
In summary, the study found a difference between the formal programme guidelines, which put no restriction on the use of funds, and those of the programme management, which tended to restrict the use of funds to healthcare and education improvement for targeted beneficiaries. Each view has its advantages and drawbacks. Since the main goal of the programme is to break the chain of intergenerational poverty, regulating the use of the transfers will ensure the fulfillment of the programme conditionality. However, this would sacrifice the opportunity of the poor to be flexible with the cash transfer and use it to fulfil their most urgent needs. Regulating its use would also restrict recipients' ability to develop an asset to increase their welfare, as has been practised in Village D. One possible option would be not to regulate the use of the fund but instead to improve compliance monitoring.

6 Their task is to make the rajungan, a kind of small crab, clean and ready for the market.

7 The Government of Indonesia (GoI) has provided the School Operational Assistance Programme to all primary and junior secondary schools and prohibited all primary and junior secondary public schools to charge school fees to the students. The GoI also provides health insurance for the poor, which gives free medication at health centres.

8 The physical stock of unhusk rice is stored in a rice mill but the facility is managed by the community and most members are rice farmers.

9 In village $A$, the fund was used for the construction of water tank and sewage canals. In Village B, the fund was used for road improvement, initial capital for women loan/savings group, and initial capital for a community rice barn. In village $\mathrm{D}$, the fund was used for the construction of a water tank and improvement of community well.

10 Names of all the following interviewees have been changed to maintain anonymity. 


\section{References}

Hutagalung, Stella A.; Arif, Sirojuddin and Suharyo, Widjajanti I. (2009) Problems and Challenges for the Indonesian Conditional Cash Transfer Program - Program Keluarga Harapan (PKH), SMERU Working Paper, Jakarta: The SMERU Research Institute

Moore, G. (2009) Nicaragua's Red de Proteccion Social: An Exemplary but Short-Lived Conditional Cash Transfer Programme, Country Study 17, Brazil: International Policy Center for Inclusive Growth

PKH (2007) Tim Penyusun Pedoman Umum PKH Lintas Kementerian dan Lembaga [Interministerial and Institution Team for the Preparation of PKH General Guideline].
Pedoman Umum Program Keluarga Harapan 2007 [General Guideline of Family of Hope Program 2007], Jakarta: Tim Penyusun Pedoman Umum PKH Lintas Kementerian dan Lembaga

Rawlings, Laura, B. and Rubio, Gloria, M. (2003) Evaluating the Impacts of Conditional Cash Transfer Program, World Bank Policy Research Working Paper 31 19, Washington DC: World Bank Skoufias, E. and Parker. S.W. (2001) CCTs and Their Impacts on Child Work and Schooling: Evidence from the PROGRESA Program in Mexico, FGND (Food Consumption and Nutrition Division) Paper 123, Washington DC: International Food Policy Research Institute (IFPRI) 